\title{
Clinical Significance of Skin Autofluorescence in Elderly Patients With Long-Standing Persistent Atrial Fibrillation
}

\author{
Takashi Hitsumoto
}

\begin{abstract}
Background: Recent clinical studies have demonstrated the importance of skin autofluorescence as a cardiovascular risk factor. However, data regarding the relationship between skin autofluorescence and atrial fibrillation are limited. The aim of this study was to clarify the clinical significance of skin autofluorescence in elderly patients with long-standing persistent atrial fibrillation.
\end{abstract}

Methods: This cross-sectional study enrolled 112 elderly patients with long-standing persistent atrial fibrillation who were treated medically (46 men and 66 women; mean age, $81 \pm 9$ years). The association between skin autofluorescence and various clinical parameters was examined.

Results: Significant relationships were observed between skin autofluorescence and $\mathrm{CHADS}_{2}$ score $(\mathrm{r}=0.53, \mathrm{P}<0.001)$, high-sensitivity cardiac troponin $\mathrm{T}$ level $(\mathrm{r}=0.43, \mathrm{P}<0.001)$, reactive oxygen metabolite levels $(\mathrm{r}=0.52, \mathrm{P}<0.001)$, and whole blood passage time $(\mathrm{r}$ $=0.45, \mathrm{P}<0.001)$. Furthermore, multiple regression analyses showed that these clinical parameters were independent variables when skin autofluorescence was used as a subordinate factor. Receiver-operating characteristic curve analysis indicated that the risk values of skin autofluorescence for high $\mathrm{CHADS}_{2}$ scores $(\geq 2)$ or elevated high-sensitivity cardiac troponin T levels $(>0.014 \mathrm{ng} / \mathrm{mL})$ were 2.6 arbitrary units (AU) and 2.7 AU, respectively.

Conclusions: The findings of this study indicated that skin autofluorescence may be a prognostic factor in elderly patients with longstanding persistent atrial fibrillation. The risk value of skin autofluorescence was considered as $2.6 \mathrm{AU}$ or $2.7 \mathrm{AU}$.

Keywords: Skin autofluorescence; Long-standing persistent atrial fibrillation; $\mathrm{CHADS}_{2}$ score; Blood rheology; High-sensitivity cardiac troponin T; Oxidative stress; Elderly

\section{Introduction}

Atrial fibrillation is a common cardiovascular disease and is as-

Manuscript submitted May 20, 2019, accepted May 27, 2019

Hitsumoto Medical Clinic, 2-7-7, Takezakicyou, Shimonoseki City, Yamaguchi 750-0025, Japan. Email: thitsu@jcom.home.ne.jp

doi: https://doi.org/10.14740/cr885 sociated with other diseases such as ischemic stroke and heart failure [1]. In recent years, the prevalence of atrial fibrillation has increased because of a concomitant increase in life expectancy [2]. Treatment via an electrophysiologic catheter ablation procedure can be performed for selected patients with atrial fibrillation [3], which may achieve a complete cure in some. Catheter ablation is particularly useful in patients with paroxysmal atrial fibrillation, but less so in those with persistent atrial fibrillation $[4,5]$. In addition, elderly patients with persistent atrial fibrillation are less likely to receive the procedure for various reasons such as duration of atrial fibrillation, symptoms, activities of daily practice, patient refusal, and limited procedural benefit.

Advanced glycation end products (AGEs) and receptors of AGEs play an important role in the pathophysiology of cardiovascular disease $[6,7]$. Among the methods used to evaluate AGEs, skin autofluorescence is known to be a simple and reliable marker of AGEs in vivo, and recent clinical studies have indicated that skin autofluorescence is significantly associated with cardiovascular disease [8-10]. However, data regarding the relationship between skin autofluorescence and atrial fibrillation are limited. This cross-sectional study attempted to clarify the clinical significance of skin autofluorescence in elderly patients with long-standing persistent atrial fibrillation.

\section{Materials and Methods}

\section{Patients}

In this study, 112 elderly outpatients (age $\geq 65$ years) with longstanding persistent atrial fibrillation who were being treated medically at the Hitsumoto Medical Clinic, Yamaguchi, Japan were enrolled between January 2017 and December 2018. Long-standing persistent atrial fibrillation (presence of atrial fibrillation for $\geq$ 1 year after initiation of rhythm control treatment) is defined by the 2010 Guidelines for the Management of Atrial Fibrillation of the European Society of Cardiology [11]. The patients included $46(41 \%)$ men and $66(59 \%)$ women. The mean patient age was $81 \pm 9$ years. The study was approved by the Institutional Review Board of the Hitsumoto Medical Clinic (approval number 201701) and was conducted in compliance with the Declaration of Helsinki. All patients provided informed consent.

\section{Measurement of skin autofluorescence}

Skin autofluorescence was measured using a commercial de- 
vice (AGE ReaderTM; DiagnOptics, Groningen, the Netherlands), as previously described [12, 13]. Autofluorescence was defined as the average light intensity per nanometer between 300 and $420 \mathrm{~nm}$. Skin autofluorescence levels were expressed in arbitrary units (AU). All measurements were performed on the volar side of the forearm approximately $10-15 \mathrm{~cm}$ below the elbow while the patients were in the sitting position. The value of pentosidine, a major component of AGEs, has been previously measured using skin biopsy on the volar side of the forearm and seemed to correlate with skin autofluorescence [14]. Previous reports have established the validity and reliability of skin autofluorescence level measurements using this method in the Japanese population [13].

\section{Evaluation of clinical parameters}

Various clinical parameters were evaluated, including classic risk factors of cardiovascular disease, such as $\mathrm{CHADS}_{2}$ score [15], echocardiographic findings, kidney function, brain natriuretic peptide level, high-sensitivity cardiac troponin $\mathrm{T}$ (hs-cTnT) level, reactive oxygen metabolites (a marker of oxidative stress), and whole blood passage time (a marker of blood rheology). Obesity was identified using body mass index, calculated as the weight $(\mathrm{kg})$ divided by the squared height $\left(\mathrm{m}^{2}\right)$. Current smoking was defined as smoking at least one cigarette per day over the previous 28 days. Hypertension was defined as systolic blood pressure $\geq 140 \mathrm{~mm} \mathrm{Hg}$, diastolic blood pressure $\geq 90 \mathrm{~mm} \mathrm{Hg}$, or the use of antihypertensive medication. Dyslipidemia was defined as low-density lipoprotein cholesterol level $\geq 140 \mathrm{mg} / \mathrm{dL}$, high-density lipoprotein cholesterol level $\leq 40 \mathrm{mg} / \mathrm{dL}$, triglyceride level $\geq 150 \mathrm{mg} / \mathrm{dL}$, or the use of lipid-lowering medication. Diabetes mellitus was defined as fasting blood glucose level $\geq 126 \mathrm{mg} / \mathrm{dL}$, hemoglobin A1c (HbA1c) level $\geq 6.5 \%$, or the use of antidiabetic medication or exogenous insulin. Standard echocardiography was performed using the HI VISION Avius ultrasound system (Hitachi Medical Corporation, Tokyo, Japan). Left ventricular wall thickness, left ventricular end-diastolic diameter, left ventricular ejection fraction, and left atrial dimension were measured by echocardiography. The estimated glomerular filtration rate was calculated using the adjusted Modification of Diet in Renal Disease Study equation, which was proposed by the working group of the Japanese Chronic Kidney Disease Initiative [16]. Brain natriuretic peptide levels were measured using the SHIONOSPOT® Reader (Shionogi \& Co., Osaka, Japan), and hs-cTnT levels were measured using an hs-cTnT assay (Roche Diagnostics, Basel, Switzerland) [17]. As an in vivo oxidative stress marker [18], the reactive oxygen metabolites (d-ROMs) test was performed (Diacron, Grosseto, Italy). Blood rheology was evaluated by measuring whole blood passage time with an MC-FAN HR300 rheometer (MC Healthcare, Tokyo, Japan), as previously reported [19, 20].

\section{Statistical analysis}

In this study, data were expressed as mean \pm standard devia- tion. Comparisons were made using the Student's $t$-test. Simple regression analysis was performed using the Pearson or Spearman rank correlation, and a multivariate analysis was performed using multiple regression. Receiver-operating characteristic curve analysis was performed, and the maximum Youden's index [21] was used to determine the optimal skin autofluorescence cutoff values for high $\mathrm{CHADS}_{2}$ scores and high hs-cTnT levels. $\mathrm{P}<0.05$ was considered to be statistically significant. StatView J5.0 (HULINKS, Tokyo, Japan) and MedCalc for Windows (MedCalc Software, Ostend, Belgium) software were used for analysis.

\section{Results}

Table 1 summarizes the patients' characteristics. The overall mean skin autofluorescence was $2.8 \pm 0.5$ AU (range, 2.0 4.6 AU). Eighty-six patients $(77 \%)$ had a $\mathrm{CHADS}_{2}$ score $\geq 2$. Figure 1 shows the significant positive correlation between skin autofluorescence and the $\mathrm{CHADS}_{2}$ score. Figure 2 shows the relationship between skin autofluorescence and the components of the $\mathrm{CHADS}_{2}$ score. Skin autofluorescence had a significant correlation with the following components: congestive heart failure, age, diabetes mellitus, and stroke/transient ischemic attack. Table 2 presents the correlation between skin autofluorescence and various clinical parameters. Smoking status, HbA1c, estimated glomerular filtration rate, brain natriuretic peptide level, hs-cTnT level, d-ROMs test, whole blood passage time, and renin-angiotensin inhibitor use significantly correlated with skin autofluorescence. Table 3 summarizes the results of multiple regression analysis with skin autofluorescence as a subordinate factor. Explanatory factors were selected by examining the multicollinearity among the variables using stepwise regression; four factors (CHADS $_{2}$ score, whole blood passage time, d-ROMs test, and hs-cTnT level) were identified as independent variables. Figure 3 shows the receiver-operating characteristic curve analysis for the detection of high $\mathrm{CHADS}_{2}$ scores $(\geq 2)$ and elevated hs-cTnT levels $(>0.014 \mathrm{ng} / \mathrm{mL})$, based on previous studies [22, 23]. The maximum Youden's index indicated that the optimal cutoff values of skin autofluorescence to determine high $\mathrm{CHADS}_{2}$ scores and elevated hs-cTnT levels were 2.6 AU and 2.7 AU, respectively.

\section{Discussion}

This study aimed to clarify the clinical significance of skin autofluorescence in elderly patients with long-standing persistent atrial fibrillation. The results showed an independent association between skin autofluorescence and $\mathrm{CHADS}_{2}$ score, whole blood passage time, hs-cTnT level, and d-ROMs test. In addition, the receiver-operating characteristic curve analysis indicated that the skin autofluorescence values associated with high $\mathrm{CHADS}_{2}$ scores and elevated hs-cTnT levels in this study population were $>2.6 \mathrm{AU}$ and $>2.7 \mathrm{AU}$, respectively.

The $\mathrm{CHADS}_{2}$ score is a well-known predictor of ischemic stroke in patients with atrial fibrillation $[15,22]$. Therefore, the 
Table 1. Patient Characteristics

\begin{tabular}{|c|c|}
\hline n (male/female) & $112(46 / 66)$ \\
\hline Age (years) & $81 \pm 9$ \\
\hline Skin autofluorescence (AU) & $2.8 \pm 0.5$ \\
\hline $\mathrm{CHADS}_{2}$ score & $3 \pm 2$ \\
\hline Body mass index $\left(\mathrm{kg} / \mathrm{m}^{2}\right)$ & $22.6 \pm 3.5$ \\
\hline Current smoker, n (\%) & $14(13)$ \\
\hline Hypertension, n (\%) & $75(67)$ \\
\hline Systolic blood pressure (mm Hg) & $131 \pm 11$ \\
\hline Diastolic blood pressure ( $\mathrm{mm} \mathrm{Hg}$ ) & $76 \pm 9$ \\
\hline Dyslipidemia, n (\%) & $76(68)$ \\
\hline Total cholesterol (mg/dL) & $218 \pm 41$ \\
\hline LDL cholesterol (mg/dL) & $137 \pm 37$ \\
\hline Triglyceride (mg/dL) & $127 \pm 66$ \\
\hline HDL cholesterol (mg/dL) & $55 \pm 15$ \\
\hline Diabetes mellitus, n (\%) & $30(27)$ \\
\hline Fasting blood glucose (mg/dL) & $104 \pm 32$ \\
\hline Hemoglobin A1c (\%) & $5.9 \pm 0.6$ \\
\hline IVSTd (mm) & $9.7 \pm 2.2$ \\
\hline LVDd (mm) & $51.5 \pm 5.9$ \\
\hline LVEF (\%) & $64.4 \pm 12.2$ \\
\hline LAD (mm) & $46.9 \pm 6.8$ \\
\hline eGFR $\left(\mathrm{mL} / \mathrm{min} / 1.73 \mathrm{~m}^{2}\right)$ & $51.8 \pm 19.1$ \\
\hline $\log -\mathrm{BNP}(\mathrm{pg} / \mathrm{mL})$ & $2.3 \pm 0.4$ \\
\hline Log-hs-cTnT (ng/mL) & $-1.8 \pm 0.4$ \\
\hline d-ROMs test (U. CARR) & $325 \pm 82$ \\
\hline WBPT (s) & $59.5 \pm 18.3$ \\
\hline \multicolumn{2}{|l|}{ Medication } \\
\hline RAS inhibitor, n (\%) & $61(55)$ \\
\hline$\beta$ blocker, n (\%) & $23(21)$ \\
\hline Diuretics, n (\%) & $31(28)$ \\
\hline Statin, n (\%) & $35(31)$ \\
\hline Warfarin/DOAC, n (\%) & $33(29) / 79(71)$ \\
\hline
\end{tabular}

Continuous values are mean $\pm \mathrm{SD}$. AU: arbitrary units; LDL: low-density lipoprotein; HDL: high-density lipoprotein; IVSTd: interventricular septal thickness at end-diastole; LVDd: left ventricular end-diastolic diameter; LVEF: left ventricular ejection fraction; LAD: left atrial dimension; eGFR: estimated glomerular filtration rate; BNP: brain natriuretic peptide; hs-cTnT: high sensitivity cardiac troponin T; d-ROMs: derivatives of reactive oxygen metabolites; WBPT: whole blood passage time; RAS: renin-angiotensin system; DOAC: direct oral anticoagulant.

independent association between skin autofluorescence and the $\mathrm{CHADS}_{2}$ score in this study suggests that increased skin autofluorescence is closely associated with ischemic stroke incidence. Although several physiologic processes are involved in ischemic stroke, vascular dysfunction is one of the main causes. Basic science studies have reported that AGEs or receptors of AGEs can induce vascular cell dysfunction [24-26].

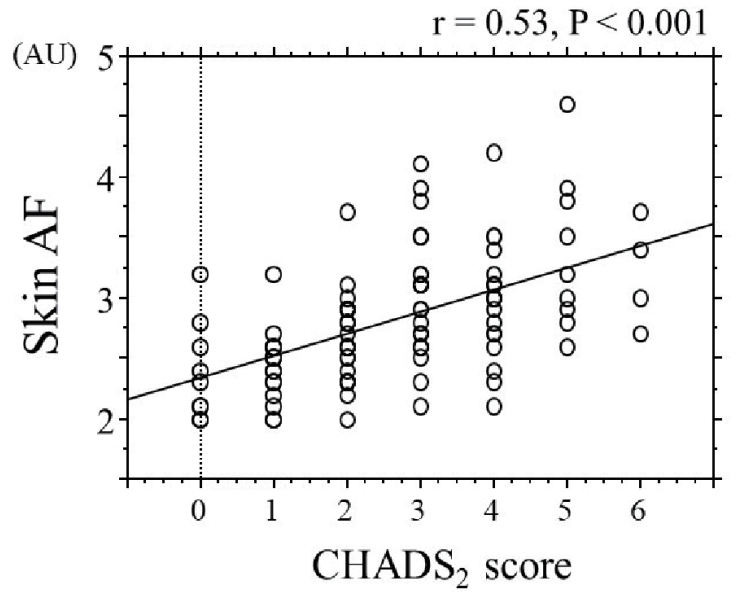

Figure 1. Correlation between skin autofluorescence and $\mathrm{CHADS}_{2}$ score. AF: autofluorescence; AU: arbitrary unit.

In addition, clinical studies have indicated a significant association between skin autofluorescence and pulsatility index at the common carotid artery, which reflects vascular resistance in cerebral vessels [27]. Thus, the relation of ischemic stroke and skin autofluorescence can be partly explained by vascular dysfunction in cerebral vessels caused by AGEs. Another mechanism of ischemic stroke is cerebral embolism, which is closely associated with atrial fibrillation. In this clinical setting, thrombosis is known to be produced mainly in the left atrium or left atrial appendage, where impaired blood rheology has been shown to be an important factor [28, 29]. Basic science investigations have indicated that AGEs cause impaired blood rheology by mechanisms such as leukocyte-endothelial interaction, activation of platelet aggregation, and increased levels of plasminogen activator inhibitor-1 [30-32]. Therefore, the independent association between skin autofluorescence and whole blood passage time in this study can be explained by hypothesizing that AGEs play an important role in impairing blood rheology in elderly patients with long-standing persistent atrial fibrillation; consequently, treatment directed at decreasing AGEs may prevent ischemic stroke by improving blood rheology.

Recent clinical studies have shown the clinical importance of hs-cTnT levels as a prognostic factor in patients with atrial fibrillation [23, 33]. In addition, hs-cTnT is used as a biomarker to clinically evaluate the severity of myocardial injury. Hofmann et al found a significant relationship between AGEmodified cardiac tissue collagen and skin autofluorescence [34]. They also showed that the AGE level found at the volar side of the forearm seemed to reflect the degree of AGE accumulation in cardiomyocytes. In addition, basic science studies have indicated that AGEs or receptors of AGEs could influence myocardial injury via several pathways $[35,36]$. Thus, the results of this study and previous ones suggest that AGEs play a crucial role in the progression of myocardial damage in elderly patients with long-standing persistent atrial fibrillation.

Several researchers have emphasized the importance of oxidative stress in the pathogenesis of atrial fibrillation [37, 38], and a number of basic science and clinical studies have 

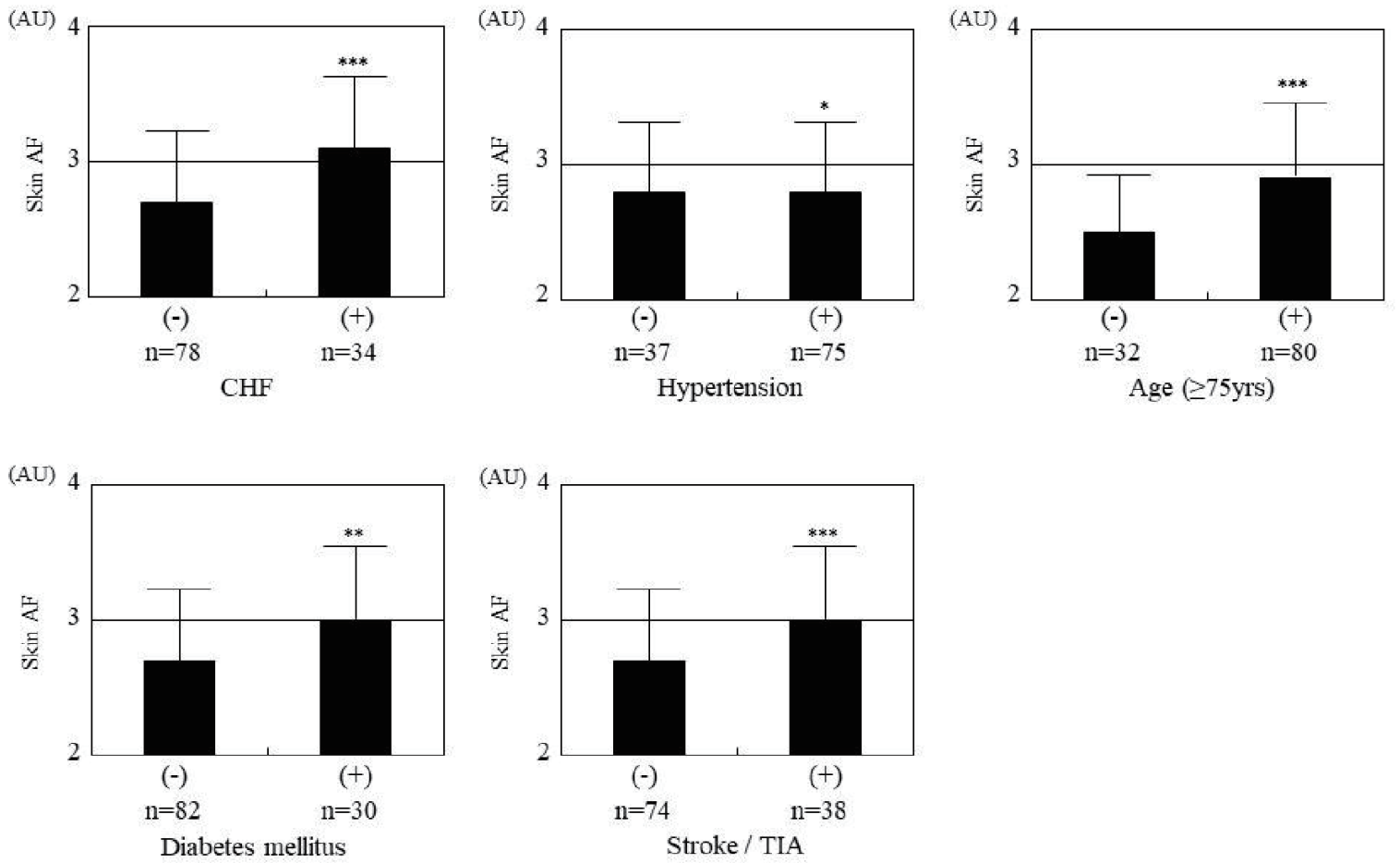

Figure 2. Relationship between skin autofluorescence and components of the $\mathrm{CHADS}_{2}$ score. Comparisons are between those with and without the following factors: $\mathrm{CHF}(3.1 \pm 0.5 \mathrm{AU}$ vs. $2.7 \pm 0.5 \mathrm{AU}$, respectively, $\mathrm{P}<0.001)$, age $\geq 75$ years $(2.9 \pm 0.5 \mathrm{AU}$ vs. $2.5 \pm 0.4 \mathrm{AU}$, respectively, $\mathrm{P}<0.001)$, diabetes mellitus ( $3.0 \pm 0.5 \mathrm{AU}$ vs. $2.7 \pm 0.5 \mathrm{AU}$, respectively, $\mathrm{P}=0.019)$, and stroke/ TIA (3.0 $\pm 0.5 \mathrm{AU}$ vs. $2.7 \pm 0.5 \mathrm{AU}$, respectively, $\mathrm{P}<0.001) .{ }^{*} \mathrm{P}=0.598,{ }^{* *} \mathrm{P}=0.019,{ }^{* * *} \mathrm{P}<0.001$. AF: autofluorescence; AU: arbitrary units; CHF: congestive heart failure; TIA: transient ischemic attack.

shown a close association between AGEs or receptors of AGEs and oxidative stress in the heart and arterial vessels [24, 39, 40]. The results of this study also indicated that the d-ROMs test as an in vivo marker of oxidative stress is an important factor for skin autofluorescence. A previous study reported that increased activity of the renin-angiotensin system caused increased oxidative stress or AGE production, and the use of an angiotensin receptor blocker decreased both oxidative stress and receptors of AGEs [41]. This study showed a significantly negative association between angiotensin receptor blocker use and skin autofluorescence, even though angiotensin receptor blocker use was not selected in the multivariate model. Therefore, we have started to intervene by prescribing an angiotensin receptor blocker for patients with high skin autofluorescence; consequently, we expect a reduction in cardiovascular events, including ischemic stroke or heart failure, in elderly patients with long-standing persistent atrial fibrillation.

This study clarified the clinical usefulness of assessing skin autofluorescence to detect a high $\mathrm{CHADS}_{2}$ score $\geq 2$ or an elevated hs-cTnT level $>0.014 \mathrm{ng} / \mathrm{mL}$, which are associated with cardiovascular events such as ischemic stroke, heart failure, and coronary artery disease in patients with atrial fibrillation according to previous reports. The receiver-operating characteristic curve analysis indicated that skin autofluorescence values $>2.6 \mathrm{AU}$ and $>2.7 \mathrm{AU}$ are the optimal cutoff points to identify a high $\mathrm{CHADS}_{2}$ score and an elevated hscTnT level, respectively. Therefore, this study indicated that maintaining skin autofluorescence values $\leq 2.6 \mathrm{AU}$ or $\leq 2.7$ $\mathrm{AU}$ in elderly patients with long-standing persistent atrial fibrillation may decrease cardiovascular events. Genevieve et al performed a study regarding the association between skin autofluorescence and HbA1c levels in patients with diabetes mellitus, and reported that skin autofluorescence was significantly associated with the means of the last five and $10 \mathrm{HbA} 1 \mathrm{c}$ values [42]. In addition, Isami et al reported that lifestyle habits such as physical activity, nonsmoking, adequate sleep, low mental stress level, eating breakfast, and abstaining from sugary foods were independently associated with lower skin autofluorescence [43]. Therefore, it appears that long-term adequate blood glucose control and good lifestyle habits are important to maintain lower skin autofluorescence as early as possible.

\section{Limitations}

This study has several limitations. First, the various medical treatments may have affected the study results. Second, skin autofluorescence was measured in only Japanese patients; previous studies have indicated that skin autofluorescence varies according to race $[44,45]$. Therefore, the cutoff values for skin autofluorescence found in this study may not apply to nonJapanese populations. Finally, the study design was a singlecenter cross-sectional study, and the sample size was relatively small. Additional prospective studies, including evaluations 
Table 2. Relationship Between Skin Autofluorescence and Various Clinical Parameters

\begin{tabular}{lll}
\hline & r & P value \\
\hline Sex $($ female $=0$, male $=1)$ & -0.14 & 0.139 \\
Body mass index & -0.13 & 0.183 \\
Current smoker $($ no $=0$, yes $=1)$ & 0.24 & 0.009 \\
Systolic blood pressure & 0.02 & 0.852 \\
Diastolic blood pressure & -0.03 & 0.732 \\
Dyslipidemia $($ no $=0$, yes $=1)$ & 0.02 & 0.852 \\
Total cholesterol & 0.02 & 0.837 \\
LDL cholesterol & 0.01 & 0.924 \\
Triglyceride & 0.05 & 0.582 \\
HDL cholesterol & -0.12 & 0.190 \\
Fasting blood glucose & 0.06 & 0.566 \\
Hemoglobin A1c & 0.24 & 0.012 \\
IVSTd & 0.02 & 0.861 \\
LVDd & 0.08 & 0.319 \\
LVEF & 0.11 & 0.251 \\
LAD & 0.19 & 0.051 \\
eGFR & -0.37 & $<0.001$ \\
Log-BNP & 0.32 & $<0.001$ \\
Log-hs-cTnT & 0.43 & $<0.001$ \\
d-ROMs test & 0.52 & $<0.001$ \\
WBPT & 0.45 & $<0.001$ \\
RAS inhibitor $($ no $=0$, yes $=1)$ & -0.16 & 0.048 \\
$\beta$ blocker $($ no $=0$, yes $=1)$ & 0.14 & 0.137 \\
Diuretics $($ no $=0$, yes $=1)$ & 0.18 & 0.062 \\
Statin $($ no $=0$, yes $=1)$ & 0.09 & 0.351 \\
Anticoagulant $($ warfarin $=0$, DOAC $=1)$ & -0.04 & 0.965 \\
\hline & & \\
\hline
\end{tabular}

r expressed correlation coefficient. LDL: low-density lipoprotein; HDL: high-density lipoprotein; IVSTd: interventricular septal thickness at enddiastole; LVDd: left ventricular end-diastolic diameter; LVEF: left ventricular ejection fraction; LAD: left atrial dimension; eGFR: estimated glomerular filtration rate; BNP: brain natriuretic peptide; hs-cTnT: high sensitivity cardiac troponin T; d-ROMs: derivatives of reactive oxygen metabolites; WBPT: whole blood passage time; RAS: renin-angiotensin system; DOAC: direct oral anticoagulant.

of interventional therapies, are required to clarify the clinical significance of skin autofluorescence in elderly patients with long-standing persistent atrial fibrillation.

\section{Conclusions}

In conclusion, the findings of this study showed that skin autofluorescence may be a prognostic factor in elderly patients with long-standing persistent atrial fibrillation. The risk value of skin autofluorescence was considered as 2.6 AU or 2.7 AU. Further prospective studies that include the evaluation of therapies are required to validate the results of this study.
Table 3. Multiple Regression Analysis for Skin Autofluorescence

\begin{tabular}{lll} 
Explanatory factor & $\boldsymbol{\beta}$ & P value \\
\hline CHADS $_{2}$ score & 0.33 & $<0.001$ \\
WBPT & 0.25 & 0.002 \\
d-ROMs test & 0.21 & 0.019 \\
Log-hs-cTnT & 0.19 & 0.020 \\
\hline
\end{tabular}

$\mathrm{R}^{2}=0.47$. WBPT: whole blood passage time; d-ROMs: derivatives of reactive oxygen metabolites; hs-cTnT: high sensitivity cardiac troponin $T ; \beta$ : standardized regression coefficient; $R^{2}$ : coefficient of determination.
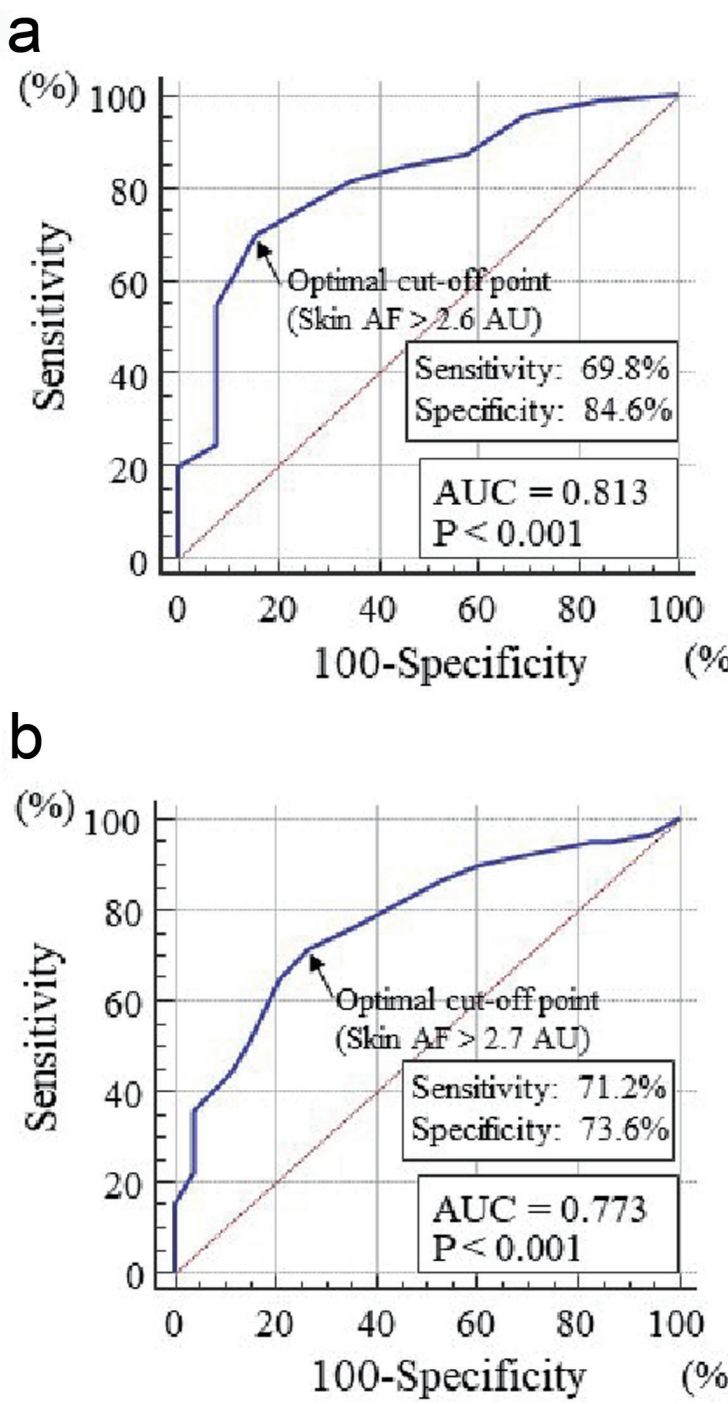

Figure 3. Receiver-operating characteristic curve analysis for the detection of high $\mathrm{CHADS}_{2}$ scores or elevated hs-cTnT levels based on skin autofluorescence. The maximum Youden's index indicated that skin autofluorescence values $>2.6 \mathrm{AU}$ and $>2.7 \mathrm{AU}$ are the optimal cutoff points to identify high $\mathrm{CHADS}_{2}$ scores $(\geq 2)$ or elevated hs-cTnT levels (> $0.014 \mathrm{ng} / \mathrm{mL}$ ), respectively. (a) $\mathrm{CHADS}_{2}$ score. (b) hs-cTnT levels. AF: autofluorescence; AU: arbitrary unit; hs-cTnT: high-sensitivity cardiac troponin T; AUC: area under the curve. 


\section{Acknowledgments}

The author is grateful to the individuals who participated in this study.

\section{Financial Disclosure}

None to declare.

\section{Conflict of Interest}

None to declare.

\section{Informed Consent}

All patients provided informed consent.

\section{Author Contributions}

The author was involved in preparing the study design as well as in the acquisition, analysis, and interpretation of data.

\section{References}

1. Stewart S, Hart CL, Hole DJ, McMurray JJ. A population-based study of the long-term risks associated with atrial fibrillation: 20-year follow-up of the Renfrew/Paisley study. Am J Med. 2002;113(5):359-364.

2. Akao M, Chun YH, Wada H, Esato M, Hashimoto T, Abe $\mathrm{M}$, Hasegawa $\mathrm{K}$, et al. Current status of clinical background of patients with atrial fibrillation in a community-based survey: the Fushimi AF Registry. J Cardiol. 2013;61(4):260-266.

3. Haissaguerre M, Jais P, Shah DC, Garrigue S, Takahashi A, Lavergne T, Hocini M, et al. Electrophysiological end point for catheter ablation of atrial fibrillation initiated from multiple pulmonary venous foci. Circulation. 2000;101(12):1409-1417.

4. Tilz RR, Rillig A, Thum AM, Arya A, Wohlmuth P, Metzner A, Mathew S, et al. Catheter ablation of longstanding persistent atrial fibrillation: 5-year outcomes of the Hamburg Sequential Ablation Strategy. J Am Coll Cardiol. 2012;60(19):1921-1929.

5. Gaita F, Caponi D, Scaglione M, Montefusco A, Corleto A, Di Monte F, Coin D, et al. Long-term clinical results of 2 different ablation strategies in patients with paroxysmal and persistent atrial fibrillation. Circ Arrhythm Electrophysiol. 2008;1(4):269-275.

6. Yamagishi S, Nakamura N, Suematsu M, Kaseda K, Matsui T. Advanced glycation end products: a molecular target for vascular complications in diabetes. Mol Med. 2015;21(Suppl 1):S32-40.

7. Koike S, Yano S, Tanaka S, Sheikh AM, Nagai A, Sugi- moto T. Advanced glycation end-products induce apoptosis of vascular smooth muscle cells: a mechanism for vascular calcification. Int J Mol Sci. 2016;17(9):1567.

8. Schmidt AM. Skin autofluorescence, 5-year mortality, and cardiovascular events in peripheral arterial disease: all that glitters is surely not gold. Arterioscler Thromb Vasc Biol. 2014;34(4):697-699.

9. Furuya F, Shimura H, Takahashi K, Akiyama D, Motosugi A, Ikegishi Y, Haraguchi K, et al. Skin autofluorescence is a predictor of cardiovascular disease in chronic kidney disease patients. Ther Apher Dial. 2015;19(1):40-44.

10. Hitsumoto T. Clinical Significance of Skin Autofluorescence in Patients With Type 2 Diabetes Mellitus With Chronic Heart Failure. Cardiol Res. 2018;9(2):83-89.

11. Camm AJ, Kirchhof P, Lip GY, Schotten U, Savelieva I, Ernst S, Van Gelder IC, et al. Guidelines for the management of atrial fibrillation: the Task Force for the Management of Atrial Fibrillation of the European Society of Cardiology (ESC). Europace. 2010;12(10):1360-1420.

12. Meerwaldt R, Hartog JW, Graaff R, Huisman RJ, Links $\mathrm{TP}$, den Hollander NC, Thorpe SR, et al. Increased accumulation of skin advanced glycation end-products precedes and correlates with clinical manifestation of diabetic neuropathy. J Am Soc Nephrol. 2005;16(12):36873693.

13. Masterson TD, Gilbert-Diamond D, Lansigan RK, Kim SJ, Schiffelbein JE, Emond JA. Measurement of external food cue responsiveness in preschool-age children: Preliminary evidence for the use of the external food cue responsiveness scale. Appetite. 2019;139:119-126.

14. Meerwaldt R, Graaff R, Oomen PHN, Links TP, Jager JJ, Alderson NL, Thorpe SR, et al. Simple non-invasive assessment of advanced glycation endproduct accumulation. Diabetologia. 2004;47(7):1324-1330.

15. Gage BF, Waterman AD, Shannon W, Boechler M, Rich MW, Radford MJ. Validation of clinical classification schemes for predicting stroke: results from the National Registry of Atrial Fibrillation. JAMA. 2001;285(22):2864-2870.

16. Imai E, Horio M, Nitta K, Yamagata K, Iseki K, Hara $\mathrm{S}$, Ura $\mathrm{N}$, et al. Estimation of glomerular filtration rate by the MDRD study equation modified for Japanese patients with chronic kidney disease. Clin Exp Nephrol. 2007;11(1):41-50.

17. Mingels A, Jacobs L, Michielsen E, Swaanenburg J, Wodzig W, van Dieijen-Visser M. Reference population and marathon runner sera assessed by highly sensitive cardiac troponin $\mathrm{T}$ and commercial cardiac troponin $\mathrm{T}$ and I assays. Clin Chem. 2009;55(1):101-108.

18. Cesarone MR, Belcaro G, Carratelli M, Cornelli U, De Sanctis MT, Incandela L, Barsotti A, et al. A simple test to monitor oxidative stress. Int Angiol. 1999;18(2):127-130.

19. Kikuchi Y, Sato K, Mizuguchi Y. Modified cell-flow microchannels in a single-crystal silicon substrate and flow behavior of blood cells. Microvasc Res. 1994;47(1):126139.

20. Hitsumoto T. Clinical impact of hemorheology on subclinical myocardial injury in patients with hypertension. J Clin Med Res. 2018;10(12):928-935. 
21. Schisterman EF, Perkins NJ, Liu A, Bondell H. Optimal cut-point and its corresponding Youden Index to discriminate individuals using pooled blood samples. Epidemiology. 2005;16(1):73-81.

22. Suzuki S, Yamashita T, Okumura K, Atarashi H, Akao M, Ogawa $H$, Inoue H. Incidence of ischemic stroke in Japanese patients with atrial fibrillation not receiving anticoagulation therapy-pooled analysis of the Shinken Database, J-RHYTHM Registry, and Fushimi AF Registry. Circ J. 2015;79(2):432-438.

23. Stoyanov KM, Giannitsis E, Biener M, Mueller-Hennessen M, Arens K, Katus HA, Vafaie M. Prognostic value of elevated high-sensitivity cardiac troponin $\mathrm{T}$ in patients admitted to an emergency department with atrial fibrillation. Europace. 2018;20(4):582-588.

24. Yamagishi S, Imaizumi T. Diabetic vascular complications: pathophysiology, biochemical basis and potential therapeutic strategy. Curr Pharm Des. 2005;11(18):22792299.

25. Chang JS, Wendt T, Qu W, Kong L, Zou YS, Schmidt AM, Yan SF. Oxygen deprivation triggers upregulation of early growth response- 1 by the receptor for advanced glycation end products. Circ Res. 2008;102(8):905-913.

26. Brett J, Schmidt AM, Yan SD, Zou YS, Weidman E, Pinsky D, Nowygrod R, et al. Survey of the distribution of a newly characterized receptor for advanced glycation end products in tissues. Am J Pathol. 1993;143(6):16991712.

27. Hitsumoto T. Impact of Hemorheology Assessed by the Microchannel Method on Pulsatility Index of the Common Carotid Artery in Patients With Type 2 Diabetes Mellitus. J Clin Med Res. 2017;9(7):579-585.

28. Siostrzonek P, Koppensteiner R, Gossinger H, Zangeneh M, Heinz G, Kreiner G, Stumpflen A, et al. Hemodynamic and hemorheologic determinants of left atrial spontaneous echo contrast and thrombus formation in patients with idiopathic dilated cardiomyopathy. Am Heart J. 1993;125(2 Pt 1):430-434.

29. Leithauser B, Jung F, Park JW. Rheological and hemostasiological aspects of thrombus formation in the left atrial appendage in atrial fibrillation? A new strategy for prevention of cardioembolic stroke. Clin Hemorheol Microcirc. 2010;45(2-4):311-323.

30. Morigi M, Angioletti S, Imberti B, Donadelli R, Micheletti G, Figliuzzi M, Remuzzi A, et al. Leukocyte-endothelial interaction is augmented by high glucose concentrations and hyperglycemia in a NF-kB-dependent fashion. J Clin Invest. 1998;101(9):1905-1915.

31. Hasegawa Y, Suehiro A, Higasa S, Namba M, Kakishita E. Enhancing effect of advanced glycation end products on serotonin-induced platelet aggregation in patients with diabetes mellitus. Thromb Res. 2002;107(6):319-323.

32. Fishman SL, Sonmez H, Basman C, Singh V, Poretsky L. The role of advanced glycation end-products in the development of coronary artery disease in patients with and without diabetes mellitus: a review. Mol Med. 2018;24(1):59.

33. Hijazi Z, Siegbahn A, Andersson U, Lindahl B, Granger
CB, Alexander JH, Atar D, et al. Comparison of cardiac troponins I and T measured with high-sensitivity methods for evaluation of prognosis in atrial fibrillation: an ARISTOTLE substudy. Clin Chem. 2015;61(2):368-378.

34. Hofmann B, Jacobs K, Navarrete Santos A, Wienke A, Silber RE, Simm A. Relationship between cardiac tissue glycation and skin autofluorescence in patients with coronary artery disease. Diabetes Metab. 2015;41(5):410-415.

35. Ma H, Li SY, Xu P, Babcock SA, Dolence EK, Brownlee M, Li J, et al. Advanced glycation endproduct (AGE) accumulation and AGE receptor (RAGE) up-regulation contribute to the onset of diabetic cardiomyopathy. J Cell Mol Med. 2009;13(8B):1751-1764.

36. Bucciarelli LG, Ananthakrishnan R, Hwang YC, Kaneko M, Song F, Sell DR, Strauch C, et al. RAGE and modulation of ischemic injury in the diabetic myocardium. Diabetes. 2008;57(7):1941-1951.

37. Samman Tahhan A, Sandesara PB, Hayek SS, Alkhoder A, Chivukula K, Hammadah M, Mohamed-Kelli H, et al. Association between oxidative stress and atrial fibrillation. Heart Rhythm. 2017;14(12):1849-1855.

38. Korantzopoulos P, Letsas K, Fragakis N, Tse G, Liu T. Oxidative stress and atrial fibrillation: an update. Free Radic Res. 2018;52(11-12):1199-1209.

39. Bodiga VL, Eda SR, Bodiga S. Advanced glycation end products: role in pathology of diabetic cardiomyopathy. Heart Fail Rev. 2014;19(1):49-63.

40. Yu Y, Wang L, Delguste F, Durand A, Guilbaud A, Rousselin C, Schmidt AM, et al. Advanced glycation end products receptor RAGE controls myocardial dysfunction and oxidative stress in high-fat fed mice by sustaining mitochondrial dynamics and autophagy-lysosome pathway. Free Radic Biol Med. 2017;112:397-410.

41. Yamagishi S, Nakamura K, Matsui T. Potential utility of telmisartan, an angiotensin II type 1 receptor blocker with peroxisome proliferator-activated receptor-gamma (PPAR-gamma)-modulating activity for the treatment of cardiometabolic disorders. Curr Mol Med. 2007;7(5):463469.

42. Genevieve M, Vivot A, Gonzalez C, Raffaitin C, Barberger-Gateau P, Gin H, Rigalleau V. Skin autofluorescence is associated with past glycaemic control and complications in type 1 diabetes mellitus. Diabetes Metab. 2013;39(4):349-354.

43. Isami F, West BJ, Nakajima S, Yamagishi SI. Association of advanced glycation end products, evaluated by skin autofluorescence, with lifestyle habits in a general Japanese population. J Int Med Res. 2018;46(3):1043-1051.

44. Simon Klenovics K, Kollarova R, Hodosy J, Celec P, Sebekova K. Reference values of skin autofluorescence as an estimation of tissue accumulation of advanced glycation end products in a general Slovak population. Diabet Med. 2014;31(5):581-585.

45. Ahmad MS, Kimhofer T, Ahmad S, AlAma MN, Mosli HH, Hindawi SI, Mook-Kanamori DO, et al. Ethnicity and skin autofluorescence-based risk-engines for cardiovascular disease and diabetes mellitus. PLoS One. 2017;12(9):e0185175. 